\title{
Assessment of cell free mitochondrial DNA as a biomarker of disease severity in different viral infections
}

\author{
Zain Ali', Shahid Waseem ${ }^{2}$, \\ Riffat Aysha Anis ${ }^{3}$, Mariam Anees ${ }^{4}$
}

\begin{abstract}
Objective: Cell Free mitochondrial DNA (CF mt-DNA) has emerged as a novel biomarker to investigate disease pathophysiology of different infections. The present study was designed to elucidate the association between CF mt-DNA, IL-6 and viral load in HIV, HBV and HCV infections and predict its role as a potential biomarker to assess the disease severity in viral infections.

Methods: Total 120 blood samples were collected from January 2018 to December 2018 of HIV, HBV and HCV patients and healthy controls (30 samples in each group). DNA and RNA were extracted from the serum to determine the levels of CF mt-DNA and viral load, respectively. IL-6 from the serum of infected individuals was quantified with ELISA.

Results: HCV patients showed the highest levels of CF mt-DNA, IL-6 and viral load, followed by HBV and HIV. Significant correlation was found between CF mt-DNA and IL-6 among the HBV patients $(p=0.017)$. However, no significant correlation of CF mt-DNA was observed with IL-6 in HIV and HCV or with the viral load in any of the three infections.

Conclusion: Elevated CF mt-DNA indicates its role in severity of viral infections. Independence of CF mtDNA expression from viral load and IL-6 in case of HIV and HCV suggests involvement of other inflammatory pathways regulating CF mt-DNA elevation.
\end{abstract}

KEYWORDS: HIV, HBV, HCV, Mitochondrial DNA, Interleukin-6.

doi: https://doi.org/10.12669/pjms.36.5.2476

How to cite this:

Ali Z, Waseem S, Anis RA, Anees M. Assessment of cell free mitochondrial DNA as a biomarker of disease severity in different viral infections. Pak J Med Sci. 2020;36(5):860-866. doi: https://doi.org/10.12669/pjms.36.5.2476

This is an Open Access article distributed under the terms of the Creative Commons Attribution License (http://creativecommons.org/licenses/by/3.0), which permits unrestricted use, distribution, and reproduction in any medium, provided the original work is properly cited.

1. Zain Ali, MPhil.

Department of Biochemistry, Quaid-i-Azam University, Islamabad, Pakistan.

2. Shahid Waseem, Ph.D.

Alpha Genomics Private Limited, Islamabad, Pakistan.

3. Riffat Aysha Anis, Ph.D.

Institute of Diet and Nutritional Sciences,

The University of Lahore, Islamabad Campus, Pakistan.

4. Mariam Anees, Ph.D.

Department of Biochemistry, Quaid-i-Azam University, Islamabad, Pakistan.

Correspondence:

Mariam Anees, PhD.

Department of Biochemistry,

Faculty of Biological Sciences,

Quaid-i-Azam University,

University Road, Post code 45320,

Islamabad, Pakistan.

E-mail: mariam@qau.edu.pk

* Received for Publication:

* Revision Received:

* Revision Accepted: *
March 17, 2020

May 9, 2020

May 15, 2020

\section{INTRODUCTION}

Assessment of inflammation at molecular level is a hallmark of disease progression studies. Mitochondria plays an important role in cellular homeostasis and inflammatory response in viral infection. ${ }^{1}$ Mitochondria shares genetic homology with prokaryotes and the recognition of mitochondrial genome in extracellular environment by immune system initiates an inflammatory response. ${ }^{2}$ Role of mitochondria in damage associated molecular patterns (DAMPs) is well established. Role of Cell free mitochondrial DNA (CF mt-DNA) in disease physiology is an emerging field in the study of new biomarkers but it still need exploration. ${ }^{3}$ In case of infections, inflammatory response by the cells respond by increasing different biomarkers i.e. C-Reactive 
Protein (CRP), IL-6, TNF-alpha and many others. ${ }^{4}$ CF mt-DNA has shown induction of TNF-alpha and IL-6 in murine models. ${ }^{5}$ Elevation of IL-6 many folds in different pathophysiological conditions is well documented. ${ }^{6}$ Viral load in case of HIV, HBV and HCV represents the replication potential of virus and disease progression to a certain extent. Viral load is predominantly first choice as a diagnostic parameter, but it may diminish within few weeks of infection. ${ }^{7}$ The need to explore biomarkers to serve the purpose of diagnosis as well as disease progression and severity requires rigorous exploring.

The present study investigates the correlation of elevated CF mt-DNA levels with IL-6 and viral load in viral infections i.e. HIV, $\mathrm{HBV}$ and $\mathrm{HCV}$ and the possibility of a potential role for CF mtDNA as a marker for disease severity and disease progression in viral infections.

\section{METHODS}

Sample Collection: Before the commencement of study, Ethical Approval was obtained from the BioEthical Committee of Quaid-i-Azam University, Islamabad (BEC-FBS-QAU2018-74, Dated: 18-0118). Individuals $(n=30)$ with HIV infection were recruited from HIV treatment centers at Pakistan Institute of Medical Sciences (PIMS), Islamabad and Peshawar. Clinical information was recorded on a structured questionnaire. $\mathrm{HBV}$ and $\mathrm{HCV}$ infected serum samples ( $\mathrm{n}=30$ each) were collected from diagnostic centers in Islamabad. Healthy controls $(n=30)$ were also included in the study. All the samples we acquired in the span of January 2018 to December 2018. Written informed consent was obtained from the subjects for collection and utilization of their samples for research purpose. Age, region and gender of the participants recruited in this study are provided in Table-I.
Extraction of nucleic acids for viral load estimation: Nucleic acids from serum samples of HIV, HBV and HCV infected individuals and healthy controls were extracted using a commercial kit (Machery-Nagel, Germany) according to the manufacturer's protocol. Extracted nucleic acids were stored at $-20^{\circ} \mathrm{C}$ until further use.

Viral load estimation: Viremia in serum samples of HIV, HBV and HCV infected individuals was analyzed on Magnetic Induction Cycler (MIC) qPCR (BMS, Australia). Serum samples (HIV, $\mathrm{HBV}$ and $\mathrm{HCV}$ ) were acquired on FAM channel while internal controls, provided in the kit, were detected on HEX channel for HBV and HCV, and on ROX channel for HIV (GeneProof and QIAGEN, Germany). Standards were included in the run to generate standard curve. Viral copies were quantified using the standard curve.

DNA extraction for CF mt-DNA analysis: DNA was extracted from $600 \mu 1$ serum of HBV and HCV infected as well as healthy individuals (control) by using organic method with slight modifications. ${ }^{8}$ Serum and plasma both were used in case of HIV patients. DNA was eluted in $80 \mu 1$ of distilled water and stored at $-20^{\circ} \mathrm{C}$ until further use.

Reference and target genes for qPCR: Primers were used to amplify regions from mitochondrial and human genomic DNA as reported earlier. ${ }^{9}$ Human beta2 microglobulin (hB2M) was used as a reference to determine the fold expression of CF mt-DNA in healthy control and patient samples. $\mathrm{hB} 2 \mathrm{M}$ primers used werehB2MF1: TGTTCCTGCTGGGTAGCTCT and hB2M R1: CCTCCATGATGCTGCTTACA. Sequence to amplify mitochondrial DNA was hmito F3: CACTTTCCACACAGACATCA and hmito R3: TGGTTAGGCTGGTGTTAGGG. Levels of CF mt-DNA were calculated with reference to the hB2M gene of cell free nuclear DNA in the serum of same samples.

Table-I: Clinical parameters of HIV, HBV and HCV infected individuals along with healthy controls.

\begin{tabular}{lcccc}
\hline & $H I V$ & $H B V$ & $H C V$ & Control \\
\hline No of Patients (n) & 30 & 30 & 30 & 30 \\
Male (\%) & 73.3 & 66.7 & 100 & 53.3 \\
Female (\%) & 26.7 & 33.3 & 0 & 46.7 \\
Mean age \pm SD & $33.167 \pm 5.546$ & $29.867 \pm 12.719$ & $30.300 \pm 12.531$ & $28.168 \pm 5.552$ \\
Age range & $25-45$ & $06-55$ & $06-57$ & $19-44$ \\
Median age & 32 & 28 & 29 & 27 \\
Punjab province (\%) & 46.7 & 33.3 & 30.0 & 33.3 \\
AJK province (\%) & 13.3 & 26.7 & 30.0 & 13.3 \\
KPK province (\%) & 40.0 & 40.0 & 40.0 & 53.3 \\
\hline
\end{tabular}

The patients did not show any clinical signs of co-infection or presence of other diseases including liver cirrhosis and cancer. 
Quantification of CF mt-DNA: Freely circulating mitochondrial and nuclear DNA contents in plasma and serum were quantified by qPCR (Magnetic Induction Cycler; BMS, Australia). Each run was monitored by a negative (no template) and a positive control. All the analyses were performed in triplicate. Real-time PCR was carried out using Eva green qPCR Master mix (Solis Biodyne, Estonia). Fold expression of CF mt-DNA was assessed by amplifying a unique mitochondrial fragment relative to hB2M gene as reference. CF mt-DNA fold expression was analyzed by Pfaffle method. ${ }^{10}$ ELISA of IL-6: IL-6 was quantified in serum samples of HIV, HBV and HCV infected individuals and healthy controls by IL-6 ELISA detection kit (Solar Bio, China) according to the manufacturer's protocol. Absorbance was measured at $450 \mathrm{~nm}$ on Multi-Skan Go (ThermoFisher Scientific, USA).

Statistical Analysis: Descriptive statistics were computed as mean \pm SEM along with range using Statistical Package for Social Sciences (SPSS) version 22. Difference of CF mt-DNA in serum and plasma was calculated by t-test. Means of CF mt-DNA, IL-6 and viral load were compared using Analysis of Variance (ANOVA). Means of groups were further separated using Tukey's post-hoc test. Correlations among various parameters were drawn using the Spearman Rho correlation coefficient. A $p$ value of $<0.05$ was considered significant and $<0.001$ was taken as highly significant.

\section{RESULTS}

Expression of CF mt-DNA in serum of HIV, HBV and $\mathrm{HCV}$ infected individuals: CF mt-DNA levels were calculated as 'fold increase' in comparison to healthy controls by real time PCR. A significant elevation of CF mt-DNA represented as mean \pm SEM was observed in the serum of HIV (7.412 \pm 1.023), HBV (104.900 \pm 26.335$)$ and HCV patients $(125.000 \pm 13.391)$ as depicted in Fig.1A and TableII. Presence of CF mt-DNA was significantly higher in HBV $(p<0.001)$ and HCV $(p<0.001)$ samples as compared to HIV as determined by One-way ANOVA and Tukey's post-hoc tests. There was no significant difference between the expression levels of CF mt-DNA in HBV and HCV patients $(p=0.684)$. Quantification of viral load in serum of HIV, $\mathrm{HBV}$ and HCV infected individuals: Viral loads were determined in all the three infections. Their comparison exhibited highest viral copy number for HCV represented as mean \pm SEM $\left(4.658 \times 10^{4} \pm\right.$ $\left.0.682 \times 10^{4}\right)$ followed by HBV $\left(3.022 \times 10^{4} \pm 0.545 \times\right.$ $\left.10^{4}\right)$ and HIV $\left(2.722 \times 10^{4} \pm 0.674 \times 10^{4}\right)$ as shown in Fig.1B and Table-II. High viral loads mean either the infection is untreated, or the body is not responding to the therapy. Although a trend was observed among the viral loads of HIV, HBV and HCV; however, the differences among the three groups were not statistically significant as determined by ANOVA probably due to high variance.

Measurement of IL-6 in serum of HIV, $\mathrm{HBV}$ and $\mathrm{HCV}$ infected individuals: IL-6 levels were measured in the serum of healthy controls as well as HIV, HBV and HCV infected individuals. Lowest IL-6 levels were observed in the healthy controls represented as mean \pm SEM $(4.833 \pm 1.647 \mathrm{pg} / \mathrm{ml})$ and a gradual increase was witnessed in HIV $(9.320 \pm 2.897)$, HBV $(13.153 \pm 1.765)$ and HCV $(20.367 \pm 4.536)$ infected individuals (Fig.1C and Table-II). Difference of IL-6 expression remained non-significant between HIV and HBV patients $(p=0.795)$ and HBV and HCV patients $(p=0.313)$; however, the difference between

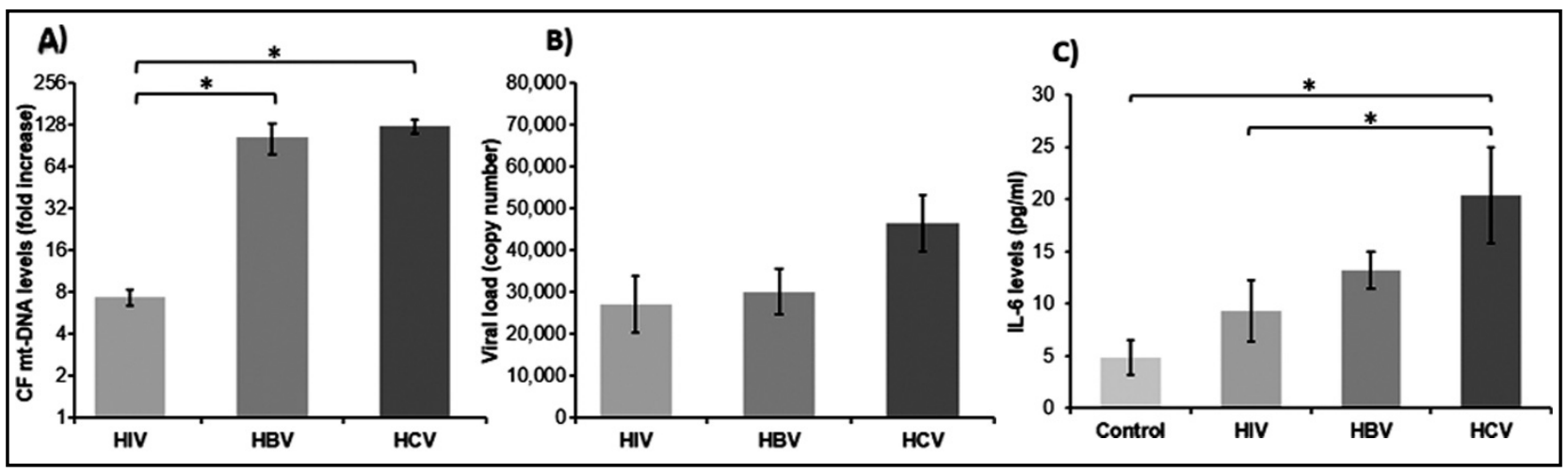

Fig.1: Comparative levels of CF mt-DNA, viral load and IL-6 in serum samples of HIV, HBV and HCV infected individuals. A) Fold-increase in CF mt-DNA levels as compared to healthy controls. B) Viral load comparison among the disease groups. C) Expression levels of IL-6 in the serum samples of infected individuals along with healthy controls. The * symbol above bars represents significant difference among groups $(\mathrm{p}<0.05)$. 
Table-II: Levels of CF mt-DNA, viral load and IL-6 in serum samples of HIV, HBV and HCV infected individuals.

\begin{tabular}{cccc}
\hline Infection & $\begin{array}{c}\text { CF mt-DNA } \\
\text { (fold increase) }\end{array}$ & $\begin{array}{c}\text { Viral Load } \\
\text { (copy number) }\end{array}$ & $\begin{array}{c}\text { Interleukin 6 } \\
(\mathrm{pg} / \mathrm{ml})\end{array}$ \\
\hline HIV & $7.412 \pm 1.023^{\mathrm{a}}$ & $27,218.182 \pm 6,736.226$ & $9.320 \pm 2.897$ \\
& $7.0 \mathrm{~b}(1-34)^{\mathrm{c}}$ & $17,000(5,700-150,000)$ & $5(0.20-87)$ \\
$\mathrm{HBV}$ & $104.900 \pm 26.335$ & $30,219.6667 \pm 5,449.475$ & $13.153 \pm 1.765$ \\
& $91.0(3-769)$ & $17,500(1,000-98,000)$ & $13(0.20-58)$ \\
$\mathrm{HCV}$ & $125.000 \pm 13.391$ & $46,584.500 \pm 6,824.206$ & $20.367 \pm 4.536$ \\
& $145.0(12-267)$ & $45,339(1,200-98,000)$ & $22(0.10-141)$ \\
\hline
\end{tabular}

${ }^{a}$ Each value represents mean \pm SEM. $\quad{ }^{\mathrm{b}}$ Each value represents median.

${ }^{c}$ Values in parenthesis represent the range of parameters.

$\mathrm{HIV}$ and $\mathrm{HCV}$ patients was statistically significant $(p=0.045)$. The control group IL-6 levels were lower than all infected groups but significantly lower than $\mathrm{HCV}$ patients only $(p=0.002)$.

Comparative expression of CF mt-DNA in HIV serum and plasma: Levels of CF mt-DNA in plasma and serum samples of HIV infected individuals were calculated. Comparative analysis showed significantly higher $(p<0.0001)$ levels of CF mtDNA in plasma $(27.309 \pm 5.029)$ of HIV infected individuals than their serum samples $(7.413 \pm 1.024)$ as shown in Fig.2A. However, both the values were independent of each other and the data did not indicate any significant correlation of CF mt-DNA in the serum and plasma samples of HIV infected individuals (Fig.2B).
Correlation between viral load and CF mt-DNA in serum samples of HIV, HBV and HCV: Spearman Rho correlation coefficient was used to see the relationship between $C F$ mt-DNA and viral load. The viral load and CF mt-DNA both were elevated in infected individuals as compared to healthy controls; however, there existed no significant correlation between viral load and CF mt-DNA in serum of HIV, HBV and HCV infected persons as shown in Fig.3A-C and Table-III. Both the entities of viral load and CF mt-DNA were independent of each other.

Correlation between CF mt-DNA and IL-6 in serum samples of $\mathrm{HIV}, \mathrm{HBV}$ and $\mathrm{HCV}$ : Presence of CF mt-DNA was also correlated with the inflammation marker IL-6. Despite of observing

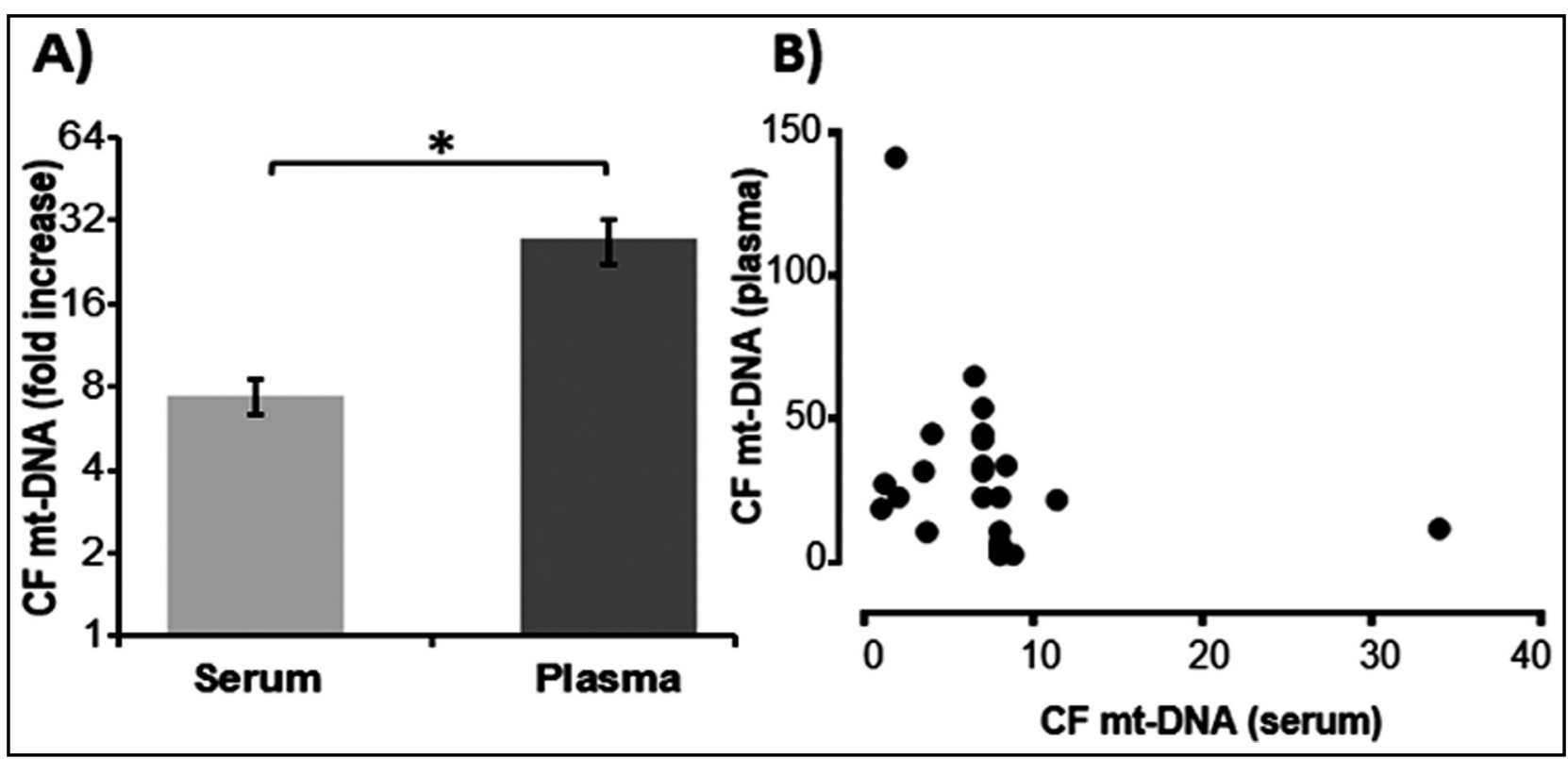

Fig.2: Comparative analysis of CF mt-DNA in serum and plasma samples of HIV infected individuals. A) Expression of CF mt-DNA was higher in plasma as compared to serum. The * symbol above bars represents significant difference among groups $(\mathrm{p}<0.05)$. B) No significant correlation was observed between the serum and plasma concentration of CF mt-DNA in HIV samples. 
Cell Free mitochondrial DNA in viral infections

Table-III: Spearman Rho correlations among the CF mt-DNA, IL-6 and viral load in three infectious groups.

\begin{tabular}{lcccccc}
\hline Variables & \multicolumn{2}{c}{$H I V$} & \multicolumn{2}{c}{$H B V$} & \multicolumn{2}{c}{$H C V$} \\
\cline { 2 - 7 } & CF mt-DNA & IL-6 & CF mt-DNA & IL-6 & CF mt-DNA & IL-6 \\
\hline \multirow{2}{*}{ Interleukin 6 } & $0.186^{\mathrm{a}}$ & & 0.432 & & 0.056 & \\
& $0.407^{\mathrm{b}}$ & & $0.017^{*}$ & & 0.768 & \\
Viral Load & -0.071 & 0.163 & -0.234 & 0.135 & 0.144 & 0.034 \\
& 0.755 & 0.496 & 0.213 & 0.477 & 0.449 & 0.858 \\
\hline
\end{tabular}

${ }^{a}$ Each value represents the value of Spearman Rho correlation coefficient $(\mathrm{R})$.

${ }^{b}$ Each value represents the level of significance $(p) . \quad$ *Significant correlation $(p<0.05)$.

high CF mt-DNA and IL-6 in all the three infections as compared to healthy controls, a direct significant correlation was observed between the two entities only in HBV patients $(\mathrm{R}=0.432 ; p=0.017)$. No significant correlation was seen between CF mt-DNA and IL-6 in HIV and
HCV infected individuals as depicted in Fig.3D-F and Table-III.

Correlation between viral load and IL-6 in serum samples of HIV, HBV and HCV: Viral load is naturally higher in viral infections and we saw high copy numbers in all the three infections. IL-6 levels

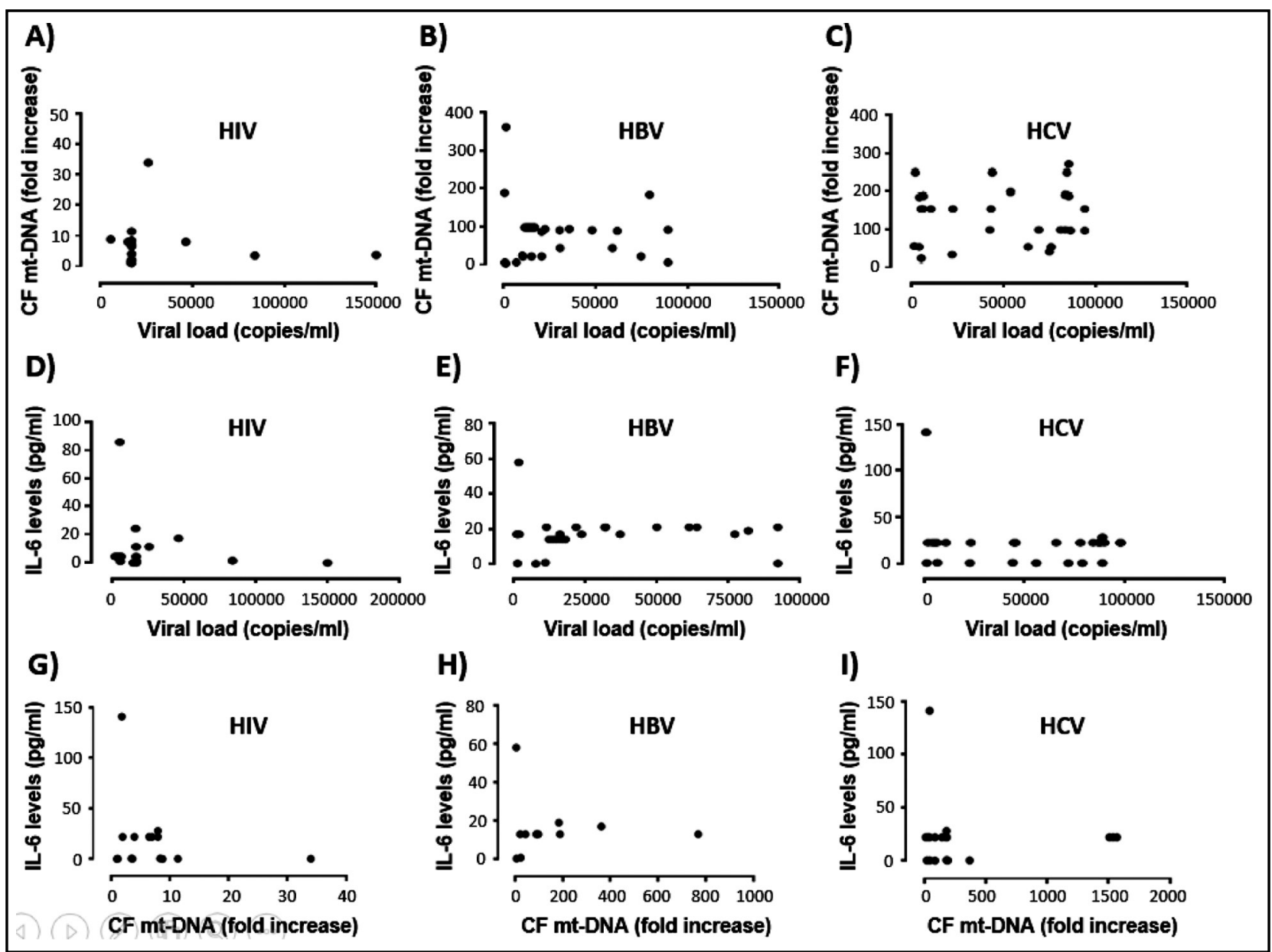

Fig.3: Spearman correlations between CF mt-DNA, viral load and IL-6 among the three disease groups. A-C) Correlations between viral load and CF-mt DNA in blood serum of HIV, HBV and HCV infected individuals. No significant correlation was observed between the two entities in any of the viral infections. D-F) Correlation between CF mt-DNA and IL-6 in blood serum of HIV, HBV and HCV infected individuals. A significant correlation was observed between the two entities only in HBV patients. G-I) Correlation between viral load and IL-6 in blood serum of HIV, HBV and HCV infected individuals. No significant correlation was observed between the two entities in any of the viral infections. 
were also higher in $\mathrm{HIV}, \mathrm{HBV}$ and $\mathrm{HCV}$ as compared to healthy controls. However, no correlation of viral load and IL-6 was found in serum of HIV, HBV and $\mathrm{HCV}$ infected individuals as given in Fig.3G-I and Table-III.

\section{DISCUSSION}

$\mathrm{HIV}, \mathrm{HBV}$ and $\mathrm{HCV}$ infections are a serious health burden in Pakistan. ${ }^{11-14}$ Diagnosis and point of care strategies require thorough understanding of infection's severity in the Pakistani population. Elevated CF mt-DNA levels have been observed in different pathophysiological conditions. ${ }^{15}$ This role of $\mathrm{CF}$ mt-DNA in different diseases make it an ideal candidate for its assessment in viral pathophysiology.

This study is the first to report the comparative analysis of CF mt-DNA in the serum of HIV, HBV and $\mathrm{HCV}$ infected individuals from Pakistan. We found higher CF mt-DNA levels in all infected individuals. A significant correlation was observed between CF mt-DNA and IL-6 in HBV infection while no such correlation was observed in HIV and HCV infections. Viral load was not significantly correlated to CF mt-DNA in any of the studied infections.

Elevated levels of CF mt-DNA in HCV infection is related to chronic and acute phases with progression into Hepatocellular carcinoma. ${ }^{16}$ Platelet activation is generally associated with elevated CF mt-DNA levels in serum. ${ }^{17}$ Platelet activation is increased in viral infections i.e. HIV and $\mathrm{HBV}$ which in turns is responsible for elevated CF mt-DNA levels. ${ }^{18}$ In case of HIV infection, integration of viral RNA into the host genome does not dictate the cell damage as it is evident in $\mathrm{HBV}$ and $\mathrm{HCV}$ infection. HIV induces apoptosis in the infected CD4 cells. ${ }^{19}$ During apoptosis, cellular contents are visualized, preventing CF mt-DNA to leach into the serum which may be a possible reason for less CF mt-DNA levels in serum of HIV than HBV and HCV in the present study. CF mtDNA levels in plasma of HIV were higher than any other infection's serum CF mt-DNA levels. Plasma contains cellular artifacts and remnants of platelets mitochondrial content which can be reason for higher CF mt-DNA levels.

IL-6 is generally known to play a dual role in inflammation by acting as anti-inflammatory cytokine through classic signaling and proinflammatory cytokine through trans-signaling. In the present study, IL-6 levels were also elevated in HIV, HBV and HCV infected individuals in comparison to healthy controls. IL-6 levels in HBV were elevated possibly due to suppressed antigen processing by Kupffer cells as reported earlier. ${ }^{20}$ Levels of IL-6 in HCV infected individuals have been reported to increase in chronic cases, prior to IFN-Gamma therapy and in non-responders to therapy. ${ }^{21}$ Serum and plasma levels of IL-6 also rise in HIV infection because of its primary role in the increased differentiation of polyclonal beta cells. ${ }^{22}$

$\mathrm{HCV}$ infected individuals exhibited higher levels of IL-6 in the serum than HBV and HIV. IL-6 is produced in response to infection and its levels are increased in most of the infections. ${ }^{23} \mathrm{HCV}$ infection induces the production of IL-6 through the enhanced expression of Toll Like Receptor 4 (TLR-4). ${ }^{24}$ Higher IL-6 levels also indicate liver cirrhosis and liver fibrosis in chronic cases of $\mathrm{HCV}$ infection. ${ }^{25}$ While in case of HBV infection, increased replication of HBV decreases the levels of IL- 6 due to the unabated nucleo-capsid formation. ${ }^{26}$ Increased levels of IL-6 in $\mathrm{HCV}$ infected individuals and decreased levels in HBV infected individuals both suggest the severity of these infections independent of their viral load, while IL-6 levels in HIV infected individuals suggest lower virulence of HIV among the infected individuals. No causal relationship between viral load and IL-6 levels has been reported earlier. ${ }^{27}$

Limitations of the study: Only patients with mono-infection were recruited for this study. Other infections i.e. HCV, HBV and TB which are commonly associated with HIV infection among Pakistani population are not represented in this study. Also, all the patients in this study were therapy-naïve. To further elucidate the role of CF mt-DNA as a biomarker for disease severity, patients on therapy should be included to assess the effectiveness of therapy and alterations in the levels of CF mt-DNA.

\section{CONCLUSION}

The present study is the first to elucidate the levels of CF mt-DNA in HIV, HBV and HCV infections among Pakistani population. Higher levels of CF mt-DNA were associated with viral infections. Elevated levels of CF mt-DNA did not co-relate with viral load in all the studied infections among the Pakistani population. This requires further investigation of the genetic variability of viral genomes which can be related to drug resistance and a possible link to increased inflammation resulting in the elevated levels of CT mt-DNA. 
Declaration of interest statement: The authors declare no conflicts of interest.

Funding Source: The project has been supported financially by Higher Education Commission Grant No. NRPU 4481 to M. A. Research associate funding is being provided to Z.A. in the same project.

\section{REFERENCES}

1. West AP, Shadel GS, Ghosh S. Mitochondria in innate immune responses. Nat Rev Immunol. 2011;11(6):389-402. doi: $10.1038 /$ nri2975

2. Boyapati RK, Rossi AG, Satsangi J, Ho G-T. Gut mucosal DAMPs in IBD: from mechanisms to therapeutic implications. Mucosal Immunol. 2016;9(3):567-582. doi: 10.1038/mi.2016.14

3. Arnalich F, Maldifassi MC, Ciria E, Codoceo R, Renart J, Fernández-Capitán C, et al. Plasma levels of mitochondrial and nuclear DNA in patients with massive pulmonary embolism in the emergency department: a prospective cohort study. Crit Care. 2013;17(3):R90. doi: $10.1186 /$ cc12735

4. Frank MO. Circulating Cell-Free DNA Differentiates Severity of Inflammation. Biol Res Nurs. 2016;18(5):477488. doi: $10.1177 / 1099800416642571$

5. Collins LV, Hajizadeh S, Holme E, Jonsson I-M, Tarkowski A. Endogenously oxidized mitochondrial DNA induces in vivo and in vitro inflammatory responses. J Leukoc Biol. 2004;75(6):995-1000. doi: 10.1189/jlb.0703328

6. Breen EC, Rezai AR, Nakajima K, Beall RT, Mitsuyasu RT, Hirano T, Kishimoto T, et al. Infection with HIV is associated with elevated IL-6 levels and production. J Immunol. 1990;144(2):480-484.

7. Selik RM, Linley L. Viral loads within 6 weeks after diagnosis of HIV infection in early and later stages: Observational study using national surveillance data. J Med Internet Res. 2018;20(11):1-12. doi: 10.2196/10770

8. Sambrook J, Russell DW. Purification of Nucleic Acids by Extraction with Phenol: Chloroform. Cold Spring Harb Protoc. 2006;2006(1):4455. doi: 10.1101/pdb.prot4455

9. Malik AN, Shahni R, Rodriguez-de-Ledesma A, Laftah A, Cunningham P. Mitochondrial DNA as a non-invasive biomarker: Accurate quantification using real time quantitative PCR without co-amplification of pseudogenes and dilution bias. Biochem Biophys Res Commun. 2011;412(1):1-7. doi: 10.1016/j.bbrc.2011.06.067

10. Pfaffl MW. Relative expression software tool (REST(C)) for group-wise comparison and statistical analysis of relative expression results in real-time PCR. Nucleic Acids Res. 2002;30(9):e36. doi: 10.1093/nar/30.9.e36

11. Rai MA, Warraich HJ, Ali SH, Nerurkar VR. HIV/AIDS in Pakistan: The battle begins. Retrovirology. 2007;4:3-5. doi: 10.1186/1742-4690-4-22

12. Asif A, Ayub S, Komal A, Noor S, Jalal U. Prevalence of human immunodeficiency virus anhepatitis (B \& C) among drug users in a tertiary care public hospital. Pak J Med Sci. 2019:35(2):459-463. doi: 10.12669/pjms.35.2.500

13. Maan M, Hussain F, Jamil M. Prevalence and risk factors of HIV in Faisalabad, Pakistan-A retrospective study. Pak J Med Sci. 2014;30(1):32-35. doi: 10.12669/pjms.301.4176

14. Asad M, Ahmed F, Zafar H, Farman S. Frequency and determinants of Hepatitis $B$ and $C$ virus in general population of Farash Town, Islamabad. Pak J Med Sci. 2015;31(6):1394-1398. doi: 10.12669/pjms.316.7047
15. Bonacini M, Louie S, Bzowej N, Wohl AR. Survival in patients with HIV infection and viral hepatitis B or C: A cohort study. Aids. 2004;18(15):2039-2045. doi: 10.1097/00002030-200410210-00008

16. Lipschitz DA, Udupa KB, Milton KV, Thompson CO. Effect of Age on Hematopoiesis in Man. Blood J. 2019;63(3):502509. doi: 10.1182/blood.V63.3.502.502

17. Lida M., Lizuka N, Sakaida I, Moribe T, Fujita N, Miura $\mathrm{T}$, et al. Relation between serum levels of cell-free DNA and inflammation status in hepatitis $C$ virus-related hepatocellular carcinoma. Oncol Rep. 2008;20:761-765. doi: 10.3892/or_00000071

18. Fusegawa H, Shiraishi K, Ogasawara F, Shimizu M, Haruki Y, Miyachi $\mathrm{H}$, et al. Platelet activation in patients with chronic hepatitis C. Tokai J Exp Clin Med. 2002;27(4):101106.

19 Turhan O, Coban E, Inan D, Yalcin AN. Increased mean platelet volume in chronic hepatitis B patients with inactive disease. Med Sci Monit. 2010;16(4):202-205.

20. Heinz D, Peters M, Prange R, Gerken G. Possible role of human interleukin-6 and soluble interleukin-6 receptor in hepatitis B virus infection. J Viral Hepat. 2001;8(3):186-193. doi: 10.1046/j.1365-2893.2001.00281.x

21. Lapinski TW. The levels of IL-1beta, IL-4 and IL-6 in the serum and the liver tissue of chronic HCVinfected patients. Arch Immunol Ther Exp (Warsz). 2001;49(4):311-316.

22. Honda M, Kitamura K, Mizutani Y, Oishi M, Arai M, Okura T, et al. Quantitative analysis of serum IL-6 and its correlation with increased levels of serum IL-2R in HIVinduced diseases. J Immunol. 1990;145(12):4059-4064.

23. Borges AH, O'Connor JL, Phillips AN, Rönsholt FF, Pett S, Vjecha MJ, et al. Factors Associated with Plasma IL-6 Levels during HIV Infection. J Infect Dis. 2015;212(4):585595. doi: 10.1093/infdis/jiv123

24. Hirano $T$, Yasukawa $K$, Harada $H$, Taga $T$, Watanabe $\mathrm{Y}$, Matsuda T, et al. Complementary DNA for a novel human interleukin (BSF-2) that induces B lymphocytes to produce immunoglobulin. Nature. 1986;324:73-76. doi: $10.1038 / 324073 \mathrm{a} 0$

25. Machida K, Cheng KTH, Sung VM-H, Levine AM, Foung S, Lai MMC. Hepatitis C Virus Induces Toll-Like Receptor 4 Expression, Leading to Enhanced Production of Beta Interferon and Interleukin-6. J Virol. 2006;80(2):866-874. doi: 10.1128/jvi.80.2.866-874.2006

26. Nakagawa H, Maeda S, Yoshida H, Tateishi R, Masuzaki $\mathrm{R}$, Ohki T, et al. Serum IL-6 levels and the risk for hepatocarcinogenesis in chronic hepatitis $\mathrm{C}$ patients: An analysis based on gender differences. Int J Cancer. 2009;125(10):2264-2269. doi:10.1002/ijc.24720

27. Shah S, Ma Y, Scherzer R, Huhn G, French A, Plankey M, et al. Association of HIV, HCV and Liver Fibrosis Severity with IL-6 and CRP levels. AIDS. 2015;29(11):1325-1333. doi: 10.1097/QAD.0000000000000654

\section{Author's Contribution:}

MA, SW, ZA: Conceptualization:

ZA: Investigation

ZA, RAA,SW: Formal Analysis and Manuscript writing:

RAA, MA: Resources

Mariam Anees is responsible and accountable for the accuracy and integrity of the work. 